\title{
Thymocyte emigration is mediated by active movement away from stroma-derived factors
}

\author{
Mark C. Poznansky, ${ }^{1}$ Ivona T. Olszak, ${ }^{1}$ Richard H. Evans, ${ }^{1}$ Zhengyu Wang, ${ }^{1}$ \\ Russell B. Foxall, ${ }^{1}$ Douglas P. Olson, ${ }^{1}$ Kathryn Weibrecht, ${ }^{1}$ Andrew D. Luster ${ }^{2}$ \\ and David T. Scadden ${ }^{1}$
}
${ }^{1}$ AIDS Research Center and Massachusetts General Hospital Cancer Center, Massachusetts General Hospital, Harvard Medical School, Boston, Massachusetts, USA
${ }^{2}$ Center for Immunology and Inflammatory Diseases, Division of Rheumatology, Allergy and Immunology,
Massachusetts General Hospital, Harvard Medical School, Boston, Massachusetts, USA

Address correspondence to: Mark C. Poznansky, Massachusetts General Hospital, Building 149 13th Street, Room 4005A, Boston, Massachusetts 02129, USA.

Phone: (617) 724-6375; Fax: (617) 726-5411; E-mail: mpoznansky@partners.org

Received for publication July 27, 2001, and accepted in revised form March 11, 2002.

T cells leave the thymus at a specific time during differentiation and do not return despite elaboration of known $\mathrm{T}$ cell chemoattractants by thymic stroma. We observed differentiation stage-restricted egress of thymocytes from an artificial thymus in which vascular structures or hemodynamics could not have been playing a role. Hypothesizing that active movement of cells away from a thymic product may be responsible, we demonstrated selective reduction in emigration from primary thymus by inhibitors of active movement down a concentration gradient (chemofugetaxis). Immature intrathymic precursors were insensitive to an emigration signal, whereas mature thymocytes and peripheral blood $\mathrm{T}$ cells were sensitive. Thymic stroma was noted to elaborate at least two proteins capable of inducing emigration, one of which was stromal cell-derived factor-1. Thymic emigration is mediated, at least in part, by specific fugetaxis-inducing factors to which only mature cells respond.

J. Clin. Invest. 109:1101-1110 (2002). DOI:10.1172/JCI200213853.

\section{Introduction}

$\mathrm{T}$ cell development in the thymus occurs in a stepwise manner and involves the sequential interaction of $T$ cell precursors with epithelial and perivascular elements in the organ $(1,2)$. As intrathymic precursors mature and exit from the thymus, they acquire coexpression of cytotoxic $\mathrm{T}$ lymphocyte antigen 4 (CTLA-4), $\mathrm{T}$ cell receptor- $\alpha \beta$, and either CD4 or CD8 $(3,4)$. Several mechanisms have been proposed to explain differentiation stage-specific $\mathrm{T}$ cell emigration from the thymus. These include downregulation of tethering adhesion molecules, passive carriage of mature $T$ cells into the endovascular space due to local fluid dynamics, and chemotaxis of mature cells toward an intravascular chemotactic agent $(1,2)$. An informative model used a transgenic mouse in which the $\mathrm{T}$ cell-specific lck promoter drove production of the $\mathrm{G}_{\alpha \mathrm{i}}$ inhibitor pertussis toxin (PTX), resulting in mature $\mathrm{T}$ cells filling an enlarged thymus without exiting to the blood or lymph nodes (5). More recently, thymic emigration from a fetal thymic organ culture was shown to be inhibitable by PTX, cytochalasin D, and Clostridium difficile toxin (3). Together, these data support the argument that mature $\mathrm{T}$ cells emigrate as a result of active cell movement mediated by a $G_{\alpha i}$ protein-coupled receptor (GPCR) and not as a result of local fluid dynamics operative in the thymus.
In exploring $\mathrm{T}$ lymphopoiesis in an in vitro system using a three-dimensional matrix, we noted differentiation stage-dependent localization of thymocytes and mature T cells leaving the matrix (6). Since neither fluid dynamics nor an external chemoattractant signal could be operative in the closed coculture system, this observation supported the postulate that maturing $\mathrm{T}$ cells actively move away from local chemokinetic factors generated within the thymic organoid.

Recently, we showed active movement of immune cells away from a chemokinetic stimulus, which we called chemofugetaxis or fugetaxis (7). Stromal cell-derived factor-1 (SDF-1), which signals cell movement via the GPCR CXCR4, induces fugetaxis of mature T cells at high concentration. Thymic stroma constitutively expresses high levels of SDF-1 RNA $(8,9)$. We therefore postulated that SDF-1 was a candidate chemokinetic agent produced by thymic stroma, possibly mediating movement of mature $\mathrm{T}$ cells away from the thymus.

\section{Methods}

Processing of human fetal thymi and the preparation of thymic stroma-conditioned medium. Human fetal thymi were obtained from human abortuses, gestational age 16-22 weeks, according to Institutional Review Board regulations. Human fetal thymic fragments of less than $1 \mathrm{~mm}^{3}$ were plated onto a $0.5-\mathrm{cm}^{3}$ piece of the biocompatible 
tantalum/carbon matrix Cellfoam (Cytomatrix, Cambridge, Massachusetts, USA) as described previously (6). Thymic stroma grew efficiently on this three-dimensional matrix in Iscove's modified Delbecco's medium (IMDM) (Life Technologies Inc., Gaithersburg, Maryland, USA) supplemented with penicillin $(100 \mathrm{U} / \mathrm{ml})$, streptomycin $(100 \mu \mathrm{g} / \mathrm{ml})$ (Sigma Chemical Co., St. Louis, Missouri, USA), and 10\% heat-inactivated bovine HIFCS (Life Technologies Inc.). After 2 weeks of culture, the matrix was confluently covered with fetal thymic stroma. The matrix was then washed gently in sterile PBS to remove nonadherent cells and placed in a culture dish containing serum-free IMDM. Serum-free thymic stroma-conditioned medium (TSCM) was harvested 48 hours later and filtered through a $0.45-\mu \mathrm{m}$ Millipore filter (Millipore Corp., Bedford, Massachusetts, USA) prior to application to a cation-exchange column. TSCM was passed through the SP cation-exchange column on the Smart System (Pharmacia, Peapack, New Jersey, USA). The column was equilibrated with $50 \mathrm{mM}$ 2-(N-Morpholino)-ethanesulfonic acid, $\mathrm{pH} 6.3$, and $0.1 \mathrm{M} \mathrm{NaCl}$. Ten $100-\mu 1$ fractions of serum-free TSCM were eluted with a linear gradient of $\mathrm{NaCl}$ concentration $(0.1-1 \mathrm{M})$. Similarly, murine thymi were obtained from $6-8$ week old C57BL/ 6 mice. Thymic fragments were cultured on the Cellfoam matrix as described, and murine TSCM was prepared once stroma reached confluence on the matrix. The generation of $T$ cells in a thymic organoid: coculture of murine thymic stroma with human hematopoietic progenitor cells. A previously described method was used to generate $\mathrm{T}$ cells from $\mathrm{CD} 34^{+}$progenitor cells (6). In brief, murine thymi were harvested from 6- to 8-week-old C57BL/6 mice. Murine thymic fragments were plated onto Cellfoam matrix units $(0.5 \times 1 \mathrm{~cm} \times 1 \mathrm{~cm}$ and a pore density of 80 pores per inch), which had been placed in the center of the wells of a 24-well tissue-culture plate and cultured for 10-14 days in IMDM and $10 \%$ heat-inactivated FCS supplemented with L-glutamine, penicillin, and streptomycin. Human CD2-CD34 ${ }^{+}$ hematopoietic progenitor cells (HPCs) were prepared from normal, healthy, adult bone marrow mononuclear cells as described previously (10). HPCs were plated onto the confluent thymic stroma. We have demonstrated previously that this coculture of progenitor cells on thymic stroma can function as a "thymic organoid" in which mature $T$ cells are generated at 14-21 days following the establishment of the coculture on the grid (6). At day 14 of the coculture, nonadherent cells were carefully harvested from the periphery of the well, and the matrix was removed. Thymic stroma was also cocultured with human $\mathrm{CD}_{3} 4^{+}$cells in the presence of pertussis toxin (PTX) $(10 \mathrm{ng} / \mathrm{ml})$ (Sigma Chemical Co.). Nonadherent cells were then washed gently from the matrix. Cells harvested from the matrix and the periphery of the well were labeled with fluorescent-conjugated anti-CD8, -CD3,-CD4, -CD14, -CD45RA, and CD45RO Ab's and examined by flow cytometry. The proportion of cells staining positive for each of the $\mathrm{T}$ cell and monocyte antigens was determined.
The preparation of human fetal thymocytes and subpopulations of fetal $T$ cells. Human fetal thymi and peripheral blood samples were obtained from 16- to 22-week abortuses according to Institutional Review Board-approved guidelines. Thymi were physically disaggregated, and mononuclear cell suspensions were generated. Thymocytes were stained with anti-CD8, -CD3, and -CD4 Ab's and sorted into purified subpopulations of triple-negative (TN) immature thymocytes $\left(\mathrm{CD}^{-}{ }^{-} \mathrm{CD} 4^{-} \mathrm{CD}^{-}\right)$and mature double-positive (DP) $\left(\mathrm{CD} 4^{+} \mathrm{CD} 8^{+}\right)$and singlepositive (SP) thymocytes $\left(\mathrm{CD}^{+} \mathrm{CD}^{+}\right.$or $\left.\mathrm{CD}^{+}{ }^{+} \mathrm{CD}^{+}\right)$by cell sorting. Fetal blood mononuclear cells (FBMCs) were prepared from fetal blood using Ficoll-Hypaque (Pharmacia). FBMCs were labeled with anti-CD8, -CD3, -CD4, -CD45RO, and -CD45RA Ab's. Thymocytes and PBMCs were obtained using Ficoll-Hypaque. PBMCs were stained with anti-CD4, -CD8, -CD45RA, and -CD45RO Ab's (Becton Dickinson Immunocytometry

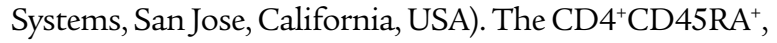
$\mathrm{CD}^{+} \mathrm{CD}_{4} \mathrm{RO}^{+}$, and $\mathrm{CD}^{+}{ }^{+} \mathrm{CD} 45 \mathrm{RA}^{+}$or $\mathrm{CD} 8^{+} \mathrm{CD} 45 \mathrm{RO}^{+}$ subpopulations of peripheral blood cells were sorted using a FACSVantage sorter (Becton Dickinson Immunocytometry Systems). The purity of each T cell subpopulation was determined to be greater than $99 \%$ by immunophenotyping. Chemokine receptor expression, including mean fluorescent intensities for chemokine receptors, were also measured and compared for each $\mathrm{T}$ cell subpopulation by staining sorted cells with anti-CXCR4 Ab (Becton Dickinson, San Diego, California, USA) directed against the cellular receptor for SDF-1. Sorted fetal peripheral blood $T$ cell and thymocyte subpopulations were cultured overnight in IMDM containing $0.5 \%$ HIFCS (Life Technologies Inc.) before their use in transmigration assays.

Transmigration assays: use of SDF- $1 \alpha$, TSCM, and TSCM fractions. Two transmigration assays were used in this study. First, quantitative transmigration assays were performed using a transwell system (Corning Costar Inc., Corning, New York, USA) (6.5-mm diameter, $5-\mu \mathrm{m}$ pore size, polycarbonate membrane) as described previously (8). Purified T cell and thymocyte subpopulations $\left(5 \times 10^{4}\right.$ cells) were added to the upper chamber of each well in a total volume of $150 \mu \mathrm{l}$ of IMDM containing 0.5\% HIFCS. Human SDF-1 (PeproTech Inc., Rocky Hill, New Jersey, USA) was used at concentrations of $10 \mu \mathrm{g} / \mathrm{ml}, 1 \mu \mathrm{g} / \mathrm{ml}, 100 \mathrm{ng} / \mathrm{ml}, 10 \mathrm{ng} / \mathrm{ml}$, and $0 \mathrm{ng} / \mathrm{ml}$ in the lower, upper, or both lower and upper chambers of the transwell to generate a checkerboard analysis matrix of positive, negative, and absent gradients of SDF-1, respectively. Similarly, TSCM was used neat or at 1:10, 1:100, and 1:1000 dilutions in serumfree medium in a checkerboard analysis matrix of positive, negative, and absent gradients of TSCM. Transmigration of T cells to fractions of TSCM as prepared above was also tested at 1:10 and 1:100 dilution in positive and negative gradients. In separate experiments, cells were pretreated for 1 hour with $100 \mathrm{ng} / \mathrm{ml}$ PTX or $10 \mu \mathrm{g} / \mathrm{ml}$ anti-CXCR 4 in a tissue-culture incubator at $37^{\circ} \mathrm{C}$ and $5 \% \mathrm{CO}_{2}$, prior to their addition to the upper 
chambers of the transwells in selected transmigration experiments. Transwells prepared in this way were incubated for 3 hours at $37^{\circ} \mathrm{C}, 5 \% \mathrm{CO}_{2}$. Cells were harvested from the lower chamber after 3 hours, and cell counts were performed using a hemocytometer.

In the second semiquantitative migration assay, $10^{6}$ mature T cells were plated into $1 \mathrm{ml}$ of $0.5 \%$ methylcellulose (Stem Cell Technologies, San Francisco, California, USA). SDF-1 at $100 \mathrm{ng} / \mathrm{ml}$ or $10 \mu \mathrm{g} / \mathrm{ml}$ was then inoculated into a fixed position in the tissue-culture well. The movement of T cells was then observed and recorded by time-lapse digital videomicroscopy for 3 hours on a heated $\left(37^{\circ} \mathrm{C}\right)$ microscope stage using a Hammamatsu image processor and software (SDR Clinical Technology, Middle Cove, Australia).

Transmigration of thymocyte subpopulations from thymic organoid or thymic fragments. Murine thymic stroma was grown to confluence on Cellfoam, and purified human and murine thymocyte subpopulations were prepared as described above. Cellfoam units with thymic stroma were gently washed in IMDM containing $0.5 \%$ heat inactivated fetal calf serum (HIFCS). Each thymic organoid was then placed in $125 \mu \mathrm{l}$ of IMDM $(0.5 \%$ HIFCS) in the upper chamber of a transwell on a polycarbonate membrane with a fixed pore size of $5 \mu \mathrm{m}$ in a 24 -well tissue-culture plate. The lower chamber of each transwell contained $500 \mu \mathrm{l}$ of medium. The transwells were then incubated for the first 3 hours at $37^{\circ} \mathrm{C}$ in an incubator containing $5 \% \mathrm{CO}_{2}$. Human fetal DP, CD $4^{+}$SP, $\mathrm{CD}^{+} \mathrm{SP}$, or T cells $\left(10^{6}\right)$ were then plated into the upper chamber and onto the thymic organoid and cultured for a further 3 hours in order to establish a gradient of thymic stroma-derived chemokinetic factors.

Thymocyte subpopulations were also treated with PTX $(100 \mathrm{ng} / \mathrm{ml})$ for 1 hour or anti-CXCR4 $(10 \mu \mathrm{g} / \mathrm{ml})$ for 30 minutes at $37^{\circ} \mathrm{C}$ prior to addition to the thymic organoid. In addition, TSCM was also added to the lower chamber in order to abrogate the gradient of thymic stroma-derived chemokinetic factors. Control experiments were also performed in which thymocyte and fetal blood $\mathrm{T}$ cell subpopulations were added to the transwell in the absence of a thymic organoid. The transwells were then returned to the incubator for a further 3 hours. At the completion of the second 3-hour incubation, cells that had emigrated from the thymic organoid in the upper chamber into the lower chamber were harvested. Harvested cells were counted using a hemocytometer.

Human fetal thymus or murine thymus was obtained as described above. Thymus was physically disaggregated into $2-\mathrm{mm}^{3}$ fragments using surgical scissors. Thymic fragments were gently washed in IMDM containing $0.5 \%$ HIFCS. Each thymic fragment was then placed in $125 \mu \mathrm{l}$ of IMDM (0.5\% FCS) in the upper chamber of a transwell on a polycarbonate membrane with a fixed pore size of $5 \mu \mathrm{m}$ in a 24-well tissue-culture plate. The lower chamber of each transwell contained $500 \mu \mathrm{l}$ of IMDM (0.5\% HIFCS). The transwells were then incubated for 3 hours at $37^{\circ} \mathrm{C}$ in an incubator containing $5 \% \mathrm{CO}_{2}$. The upper transwell was then gently transferred and placed over a lower well containing freshly aliquoted IMDM with $0.5 \%$ HIFCS in order to establish a gradient of thymic stroma-derived chemokinetic factors. The transwells were then returned to the incubator for a further 3 hours. At the completion of the second 3 hours, incubation cells that had emigrated from the thymic fragment in the upper chamber into the lower chamber were harvested. Harvested cells were counted using a hemocytometer and immunophenotyped using anti-CD8, -CD3, and -CD4 Ab's to define the proportion and absolute number of SP and DP thymocytes that had emigrated from each individual thymic fragment.

The following inhibitors were then added to the upper chamber containing the thymic fragment and the lower chamber containing $500 \mu \mathrm{l}$ of freshly prepared IMDM containing 0.5\% HIFCS: anti-CXCR4 (20 $\mu \mathrm{g} / \mathrm{ml}$ ) (PharMingen, San Diego, California, USA), PTX $(100 \mathrm{ng} / \mathrm{ml})$, genistein $(1 \mu \mathrm{g} / \mathrm{ml})$, wortmannin $(1 \mu \mathrm{M})$, 8-bromo-cAMP (8-Br-cAMP; $100 \mu \mathrm{M})$, or 8-Br-cGMP $(100 \mu \mathrm{M})$ (Sigma Chemical Co.), $2 \%$ paraformaldehyde (Sigma Chemical Co.), or undiluted TSCM. Transwells prepared in this way were incubated for a third period of 3 hours at $37^{\circ} \mathrm{C}$ in a $5 \% \mathrm{CO}_{2}$ incubator. Cells emigrating into the lower chamber from each of the thymic fragments were harvested, and cell counts and immunocytochemical analysis of thymocyte subpopulations were performed as described above. The absolute change in the number and immunophenotype of cells emigrating from each thymic fragment in the absence and presence of an inhibitor was then determined. We had demonstrated previously that, under control conditions and in the absence of inhibitors, there was no significant change in the number or immunophenotype of cells emigrating from the thymic fragment during the first as compared with the second 3-hour incubation.

\section{Results}

Emigration of SP thymocytes and peripheral blood T cells from a thymic organoid or fragment is differentiation stage-specific and PTX-inhibitable. We have established an in vitro system in which bone marrow-derived stem/progenitor cells undergo T cell differentiation (6). The system consists of a coculture of murine thymic stroma and primitive hematopoietic cells on a three-dimensional grid. The system resembles $T$ cell development in the thymus, with the production of immature $\mathrm{DP} \mathrm{CD} 4^{+} \mathrm{CD} 8^{+}$ thymocytes and the ultimate emergence of mature SP $\mathrm{CD}^{+}{ }^{+} \mathrm{CD} 4^{+} \mathrm{CD}^{-}$and $\mathrm{CD}^{+}{ }^{+} \mathrm{CD}^{-}{ }^{-} \mathrm{CD} 8^{+} \mathrm{T}$ cells containing a high frequency of $\mathrm{T}$ cell receptor excision circles. The interval from stem/progenitor to SP thymocyte generation is 14 days. SP and DP thymocytes are not found within or outside the thymic organoid prior to this time, as shown in Figure 1a. At 14 days, SP CD4 ${ }^{+}$ and $\mathrm{CD}^{+} \mathrm{T}$ cells were found at the periphery of the tissue-culture well (Figure 1b). SP thymocyte localization 

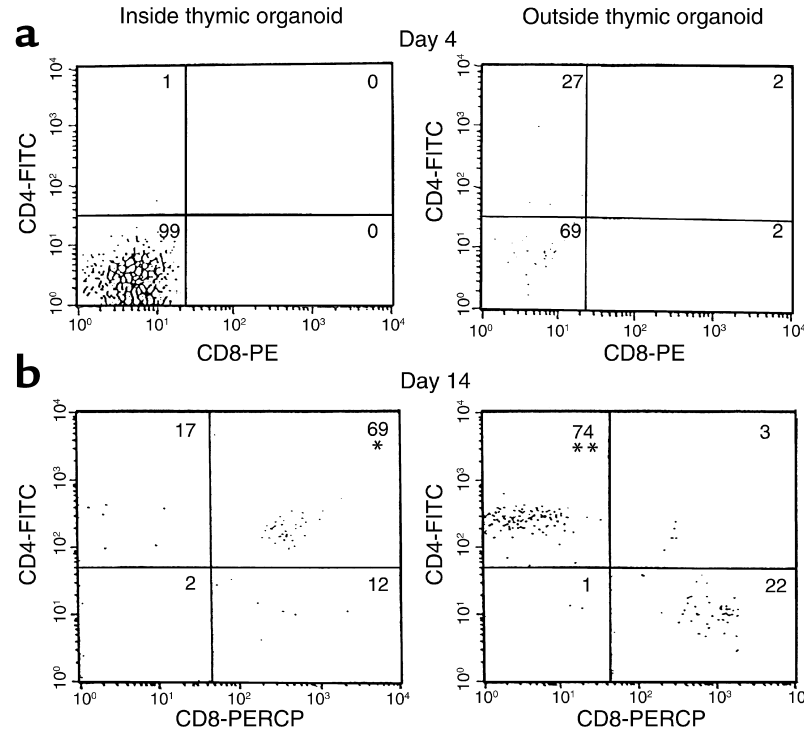

Day 14
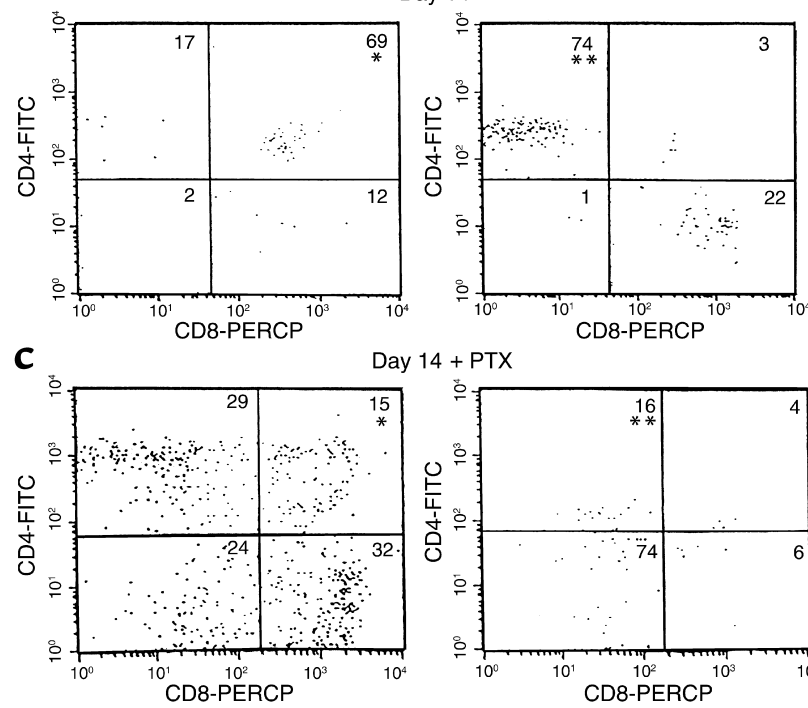

ay $14+$ PTX

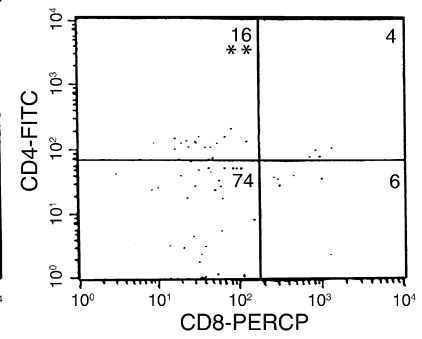

\section{Figure 1}

Mature SP T cells migrate away from the thymic stroma/CD34 ${ }^{+} \mathrm{CD} 2^{-}$ cell coculture in which they are generated. Purified human bone marrow-derived $\mathrm{CD} 34^{+} \mathrm{CD} 2^{-}$hematopoietic progenitor cells were plated onto confluent murine thymic stroma established on the three-dimensional matrix Cellfoam to form a thymic organoid. A sample of cells was harvested from inside and outside the thymic organoid under microscopic guidance at day 4 (a) and day $14(\mathbf{b})$ and stained with anti-CD4 (FITC-labeled) and anti-CD8 (PERCP- or PE-labeled). The thymic organoid was also cultured in the presence of PTX $(10 \mathrm{ng} / \mathrm{ml})$ between day 7 and day 14, and cells were harvested and analyzed at day 14 (c). At day 14 of the coculture, cells began to appear at the edge of cultures away from the thymic stroma-coated Cellfoam. At day 14 the majority of cells from the periphery of the coculture were $\mathrm{CD} 4^{+} \mathrm{CD} 8^{-}$or $\mathrm{CD} 4^{-} \mathrm{CD} 8^{+}$, whereas the majority of cells within the Cellfoam were $\mathrm{CD}^{+} \mathrm{CD}^{+}(\mathbf{b})$. At day 14 , in the culture containing the thymic organoid exposed to PTX, the majority of cells were detected in the grid and were either $\mathrm{CD}^{+} \mathrm{CD} 8^{+}$and $\mathrm{CD} 4^{+} \mathrm{CD} 8^{-}$or $\mathrm{CD} 4^{-} \mathrm{CD} 8^{-}$thymocytes. A very small proportion of $\mathrm{CD}^{+}{ }^{+} \mathrm{CD} 8^{-}$and $\mathrm{CD} 4^{-} \mathrm{CD} 8^{-}$thymocytes was detected outside of the thymic organoid in these PTXtreated cultures (c). The percentage of cells falling into each immunophenotypic category is shown in the top right corner of each quadrant. ${ }^{*} P<0.05,{ }^{*} P<0.01$, Student $t$ test.

at the periphery was significantly reduced $(P<0.01$, Student $t$ test $)$ when cocultures were exposed to PTX (Figure 1c). CD34+CD2- or TN CD3-CD4-CD8cells were only detectable at the periphery of the culture up to 4-5 days after seeding the thymic stroma with primitive hematopoietic cells (Figure 1a). Primitive stem cells or TN thymocytes were not detected in significant numbers at the periphery of the culture after this time (Figure 1b).
To further substantiate the differentiation stagespecific emigration of thymocytes from the thymic organoid and its dependence on a PTX-inhibitable signal transduction pathway, purified subpopulations of human thymocytes were plated onto a thymic organoid containing stromal cells alone. The thymic organoid was placed on a polycarbonate membrane of a fixed, $3-\mu \mathrm{m}$ pore size within the upper chamber of a transwell. Purified subpopulations of human or murine $\mathrm{TN}$, DP, or SP thymocytes were then plated onto the stroma. Transmigration of thymocyte subpopulations from the grid was then quantitated. There were marked differences between the transmigration of different thymocyte subpopulations. Migration of immature DP thymocytes away from thymic stroma was minimal, with $4.1 \% \pm 0.3 \%$ of input cells transmigrating (Figure 2a). In marked contrast, a significantly greater $(P<0.001$, Student $t$ test $)$ proportion of SP thymocytes $\left(\mathrm{CD}^{+} \mathrm{SP}, 8.9 \% \pm 1.0 \%\right.$; $\left.\mathrm{CD}^{+} \mathrm{SP}, 13.4 \% \pm 1.5 \%\right)$ transmigrated to the lower chamber of the transwell away from thymic stroma (Figure 2). Migration of SP thymocytes away from thymic stroma was significantly inhibited following exposure to PTX $\left(\mathrm{CD}^{+} \mathrm{SP}\right.$ thymocytes, $2.9 \% \pm 0.2 \%$; $\mathrm{CD}^{+}$SP thymocytes, $2.2 \% \pm 0.1 \%$; $P<0.0001$, Student $t$ test). Migration of SP thymocytes was also abrogated when the gradient of thymic stromal chemokinetic factors was nullified by adding TSCM to both the upper and lower chambers of the transwell (Figure 2a). The transmigration of thymocyte subpopulations and fetal blood $\mathrm{T}$ cells was also studied in the absence of a thymic organoid (Figure 2a). Spontaneous migration of thymocyte and fetal blood T cell subpopulations was significantly less than directional movement away from the thymic organoid under these conditions.

Emigration of thymocytes from the thymus was also examined in a system that more closely resembles the physiological setting. Freshly prepared murine thymic fragments were placed on a polycarbonate membrane of a fixed, $3-\mu \mathrm{m}$ pore size within the upper chamber of a transwell.

Emigration of TN, SP, and DP thymocytes from the thymic fragment into the lower chamber was then quantitated by cell counting and flow cytometry. Migration of both $\mathrm{CD}^{+}$and $\mathrm{CD} 8^{+} \mathrm{SP}$ thymocytes away from the thymic fragment was significantly greater than that for immature TN $(P<0.0001$, Student $t$ test $)$ and DP thymocyte subpopulations $(P<0.0001$, Student $t$ test) (Figure $2 \mathrm{~b}$ ). Similar to the thymic organoid, emigration of SP thymocytes from the thymic fragment was inhibitable by exposure to PTX or by abrogation of the gradient of thymic stroma-derived chemokinetic factors by the addition of TSCM to both upper and lower chambers of the transwell. Pretreatment of thymic fragments with paraformaldehyde significantly inhibited emigration of SP thymocytes, thus confirming that movement of SP thymocytes away from the thymic gradient was an active process and not simply passive movement of cells through the pores of the transwell membrane. 
Emigration of SP thymocytes and peripheral blood T cells is dependent on a gradient of thymic stromal chemokinetic fac$\operatorname{tor}(s)$. As demonstrated above, the addition of TSCM to both the upper and lower chambers of the transwell system involving both thymic organoid and thymic fragment abrogated differentiation stage-specific emigration of both SP thymocytes and fetal blood T cells. We therefore postulated that movement of SP thymocytes and $\mathrm{T}$ cells was dependent on a gradient of a thymic stromal chemokinetic factor or factors generated in the upper chamber by the thymic organoid or fragment.

To further examine the dependence of SP thymocyte and fetal blood $\mathrm{T}$ cell emigration on a gradient of thymic stroma-derived chemokinetic factor(s), a checkerboard analysis of thymocyte and fetal blood T cell migration to serial dilutions of TSCM was performed (Figure 3). The transmigration of thymocyte and peripheral blood $\mathrm{T}$ cell subpopulations in response to positive and negative gradients of serial dilutions of TSCM was assessed using a checkerboard analysis of cell migration. TN and DP thymocytes showed negligible chemotactic and fugetactic responses to TSCM that was undiluted or diluted 1:10 or 1:100 in serum-free medium (data not shown). Fetal peripheral blood T cells demonstrated a peak chemotactic response to $1: 10$ TSCM under which conditions $6.3 \% \pm 0.7 \%$ of cells transmigrated. In contrast, $9.3 \% \pm 0.8 \%$ of input fetal $\mathrm{T}$ cells moved away from undiluted TSCM (Figure 3). Directional responses both toward and away from TSCM were significantly greater than chemokinesis (random movement) seen at either dilution of TSCM in the absence of a gradient. Furthermore, preincubation of fetal blood T cells in TSCM prior to exposure of these cells to gradients of the known chemoattractant SDF-1 did not effect cell movement toward or away from the chemokine (data not shown). Therefore, these data support the view that gradients of TSCM induce directional movement of fetal blood $\mathrm{T}$ cells rather than blocking cellular movement.

SP thymocytes also demonstrated a maximal chemotactic response to $1: 10 \mathrm{TSCM}(8.8 \% \pm 1.1 \%$ of input cells $)$ and moved away from undiluted TSCM $(12.5 \% \pm 1.5 \%$ of input cells) (data not shown). These data further supported the postulate that differentiation stage-specific movement of thymocyte populations away from thymic stromal chemokinetic factors was gradient-dependent. Thymic stroma-derived SDF-1 contributes to thymocyte emigration from the thymic organoid and thymic fragment and is mediated via the chemokine receptor CXCR4. We have demonstrated previously that mature human $\mathrm{T}$ cells actively move away from the chemokine SDF-1, a mechanism we termed fugetaxis or chemofugetaxis (7). Furthermore, since hemodynamic effects or chemotactic recruitment postulated for the native thymus could not be present to explain emigration from the thymic organoid or fragment, we assessed whether SP thymocytes may undergo fugetaxis or active movement away from SDF-1 generated by thymic stroma. The feasibility of this phenomenon was demonstrated in semisolid cultures in which SDF-1 was added at differing concentrations at specific locations in the culture. Distinct movement characteristics and directions were noted at low concentrations (movement toward SDF-1: chemotaxis) and
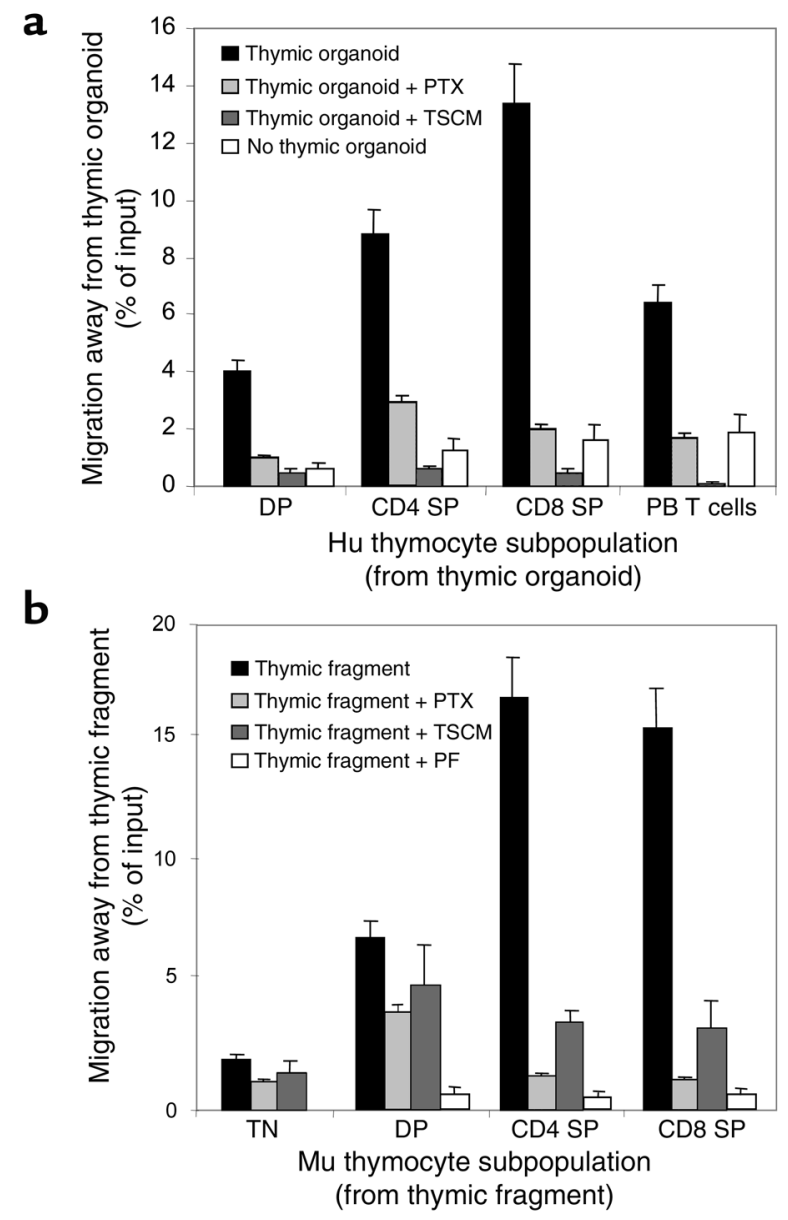

Figure 2

(a) Emigration of thymocyte and peripheral blood T cells from the thymic organoid. Purified human ( $\mathrm{Hu}) \mathrm{CD}^{+}$and $\mathrm{CD}^{+} \mathrm{SP}$ thymocytes, DP CD4 $4^{+} \mathrm{CD} 8^{+}$thymocytes, and fetal blood $\mathrm{T}$ cells were plated onto a grid coated with thymic stroma in the upper chamber of a transwell. Emigration from the upper chamber into the lower chamber was quantitated (black bars). Cells in the upper chamber were also pretreated with PTX (light gray bars), or TSCM was added to the upper and lower chambers before the addition of thymocytes (dark gray bars). Thymocyte populations or fetal blood T cells were also plated into the upper chamber in the absence of thymic stroma (white bars). The percentage of cells emigrating under each condition was assessed in three independent experiments, and the mean migration with SE bars is shown. (b) Emigration of thymocytes and peripheral blood $\mathrm{T}$ cells from murine ( $\mathrm{Mu}$ ) thymic fragments. Murine thymic fragments were placed in the upper chamber of a transwell. Emigration of TN $\left(\mathrm{CD}^{-}{ }^{-} \mathrm{CD} 4^{-} \mathrm{CD} 8^{-}\right)$, DP $\left(\mathrm{CD}^{+}{ }^{+} \mathrm{CD} 8^{+}\right)$, and SP $\left(\mathrm{CD} 4^{+}\right.$and $\left.\mathrm{CD}^{+}\right)$thymocytes from the thymic fragment into the lower chamber was quantitated (black bars). Thymic fragments in the upper chamber were also pretreated with PTX (light gray bars), murine TSCM was added to the upper and lower chambers prior to the addition of the fragment (dark gray bars), or thymic fragments were pretreated with paraformaldehyde (PF) (white bars). The percentage of cells emigrating under each condition was assessed in three independent experiments. The mean migration with SE bars is shown. 


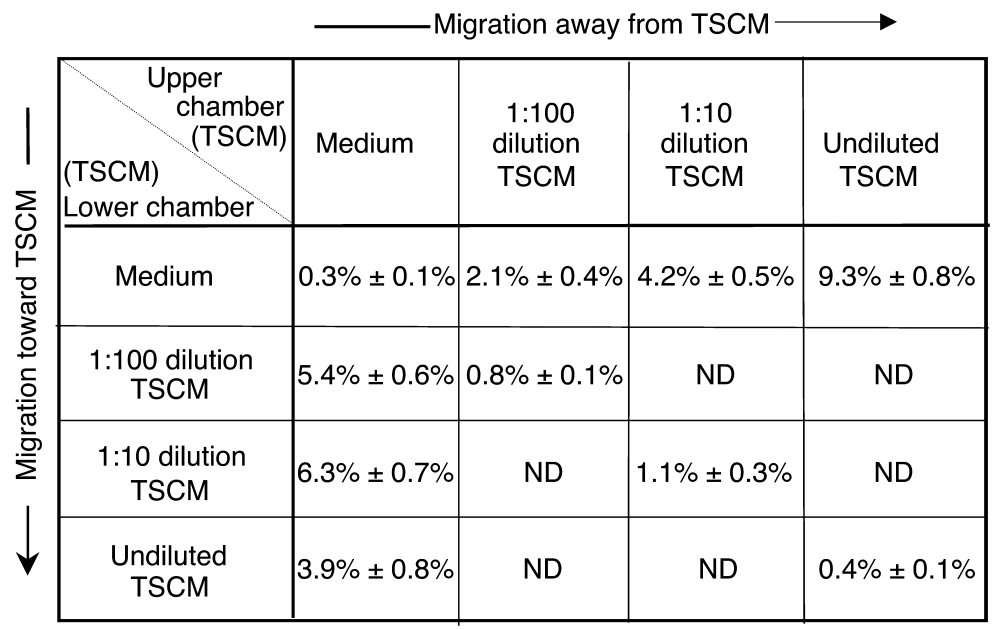

\section{Figure 3}

Checkerboard analysis of migratory responses of fetal T cells to TSCM. Numbers shown represent mean number of cells \pm SEM, from three independent experiments, that migrated through a polycarbonate membrane with a $5-\mu \mathrm{m}$ pore size into the lower chamber of a transwell. Human fetal blood T cells were counted in the lower chamber 3 hours after the introduction of $5 \times 10^{4}$ cells into the upper chamber, and human TSCM was added at the indicated dilutions in the upper chamber (above diagonal), creating a negative gradient, or the lower chamber (below diagonal), creating a positive gradient. Squares along the diagonal represent cell migration in the presence of TSCM in the absence of a gradient and correspond to chemokinesis or random movement. ND, not determined. high concentration (movement away from SDF-1: fugetaxis) (see supplemental data, www.jci.org/cgi/ content/full/109/8/1101/DC1). Directional movement of four representative cells was documented for each of the three video clips using image analysis (Figure 4). This study demonstrates that the cells move consistently toward SDF- 1 at a peak concentration of $100 \mathrm{ng} / \mathrm{ml}$ at an approximate speed of $8.4 \mu \mathrm{m} / \mathrm{min}$ and away from SDF-1 at a peak concentration of 10 $\mu \mathrm{g} / \mathrm{ml}$ at $6.8 \mu \mathrm{m} / \mathrm{min}$. These data provided support for active repulsion of mature $\mathrm{T}$ cells from high concentrations of SDF-1 in the thymus as a possible mechanism for $\mathrm{T}$ cell emigration from the thymus.

We next assessed whether thymic stroma produced high concentrations of SDF-1. TSCM was prepared from confluent cultures of human thymic stroma grown on Cellfoam. Ion exchange chromatography was performed and fractions collected for assessment of biological activity and biochemical analysis. One peak of fugetactic activity was noted in fraction 9, which was inhibitable by neutralizing $\mathrm{Ab}$ to $\mathrm{CXCR} 4$, the receptor for SDF-1 ( $P<0.001$, Student $t$ test). In addition, a second peak of activity was noted in fraction 4 . Movement of $\mathrm{T}$ cells away from fraction 4 was inhibited by antiCXCR4, but this did not reach statistical significance $(P<0.1$, Student $t$ test) (Figure 5). Both fractions inducing fugetaxis were inhibitable by PTX. Western blot analysis demonstrated SDF-1 in fraction 9. The approximate concentration of SDF-1 in TSCM was estimated from the Western blot at $1.3 \mu \mathrm{g} / \mathrm{ml}$ when compared with the control blot for recombinant SDF-1 containing 100 ng of the chemokine. Fraction 4 did not immunoblot with anti-SDF-1. This fraction was not apparent in bone marrow stroma-conditioned medium (data not shown). These data suggest that a specific fraction of TSCM contained a high concentration of SDF-1 that could elicit active movement of mature $T$ cells away from it. This migratory response to the fraction containing SDF-1 was inhibitable by pretreatment of $\mathrm{T}$ cells with an mAb that blocks the chemokine-binding site on its sole receptor, CXCR4.
Three experimental approaches were then used to determine the role that active movement of thymocyte populations away from SDF-1 played in thymic emigration: the quantitation of CXCR4 expression on thymocyte subpopulations, the study of the effects of CXCR 4 blockade, or the abrogation of an SDF-1 gradient on thymocyte migratory responses from the thymic organoid or fragment and the effect of inhibitors known to inhibit components of the signal transduction signaling movement toward or away from SDF-1.

All subpopulations of peripheral blood $\mathrm{T}$ cells and thymocytes were shown to express CXCR4 at high levels, as determined by flow cytometry (Table 1). Our data confirm the finding of CXCR 4 on both immature DP and mature SP thymocyte populations, as well as mature peripheral blood $T$ cell subpopulations.

We then examined the role of the SDF-1/CXCR4 axis in the differentiation stage-specific emigration of SP

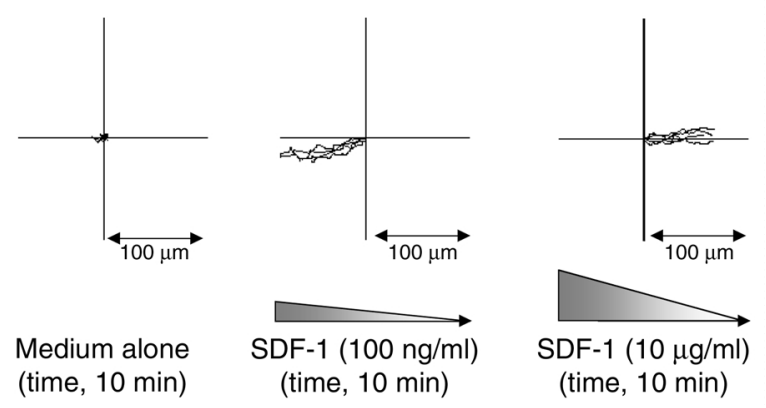

\section{Figure 4}

Quantitation ofT cell movement depicted in time-lapse digital video microscopy. Quantitation of human T cell movement during each video clip (see supplemental data, www.jci.org/cgi/content/full/109/ $8 / 1101 / D C 1)$. The speed and direction of movement was plotted for each of four representative cells in each of the video clips: left, medium alone; middle, SDF-1 at a peak concentration of $100 \mathrm{ng} / \mathrm{ml}$; right, SDF-1 at a peak concentration of $10 \mu \mathrm{g} / \mathrm{ml}$. The position of each cell at the beginning of each video clip and the movement away from that point are plotted. The paths of each cell were then overlaid. The direction of the gradient and the scale are shown for each condition. Cells migrate toward SDF- 1 in the middle plot and away from SDF-1 in the right plot. 


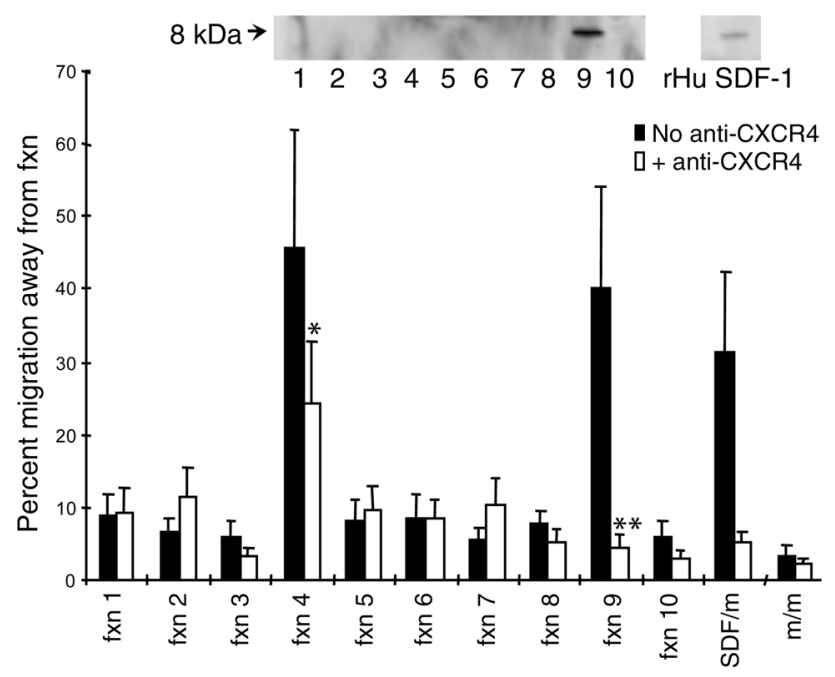

Figure 5

Fugetactic activity is present in two fractions of human TSCM prepared on a cation column, one with undetectable SDF-1 and a second containing SDF-1. A 1:10 dilution of column fractions (Fxn 1-10) derived from an SP cation-ion-exchange column eluted with a linear gradient of $\mathrm{NaCl}$ concentration (0.1-1 M) was used in experiments. The fugetactic activity was determined using a standard transwell assay system. Each fraction was loaded into the upper chamber of the transwell alone, and the migration of $\mathrm{CD} 4{ }^{+} \mathrm{CD} 45 \mathrm{RO} T$ cells away from the fraction was quantitated as described above. Fractions 4 and 9 contained fugetactic activity for $\mathrm{CD} 4{ }^{+} \mathrm{CD} 45 \mathrm{RO} T$ cells. The fugetactic activity of fraction 9 alone was inhibitable if $T$ cells were preincubated with anti-CXCR4. The control fugetactic activity of $1 \mu \mathrm{g} / \mathrm{ml}$ SDF-1 $(\mathrm{SDF} / \mathrm{m})$ and medium alone $(\mathrm{m} / \mathrm{m})$ was also tested. Each data point represents the mean and SEM of three independent experiments. Fractions of TSCM prepared on a cation-exchange column were analyzed by Western blot with a polyclonal goat anti-human SDF-1 Ab (R\&D Systems Inc., Minneapolis, Minnesota, USA) and a peroxidase-conjugated secondary $A b$. Only fraction 9 and control recombinant human $(\mathrm{rHu}) \mathrm{SDF}-1(100 \mathrm{ng})$ generated a positive band of approximately $8 \mathrm{kDa}$ (inset). ${ }^{*} P<0.1,{ }^{*} P<0.001$, Student $t$ test.

thymocytes from the thymic organoid and thymic fragment. Purified subpopulations of human thymocytes were applied to the thymic organoid, and emigration of these cells was then quantitated as described above. Thymocyte subpopulations were exposed to anti-CXCR4 prior to addition onto the thymic organoid (Figure 6a). Anti-CXCR4 was shown to significantly inhibit the active movement of $\mathrm{CD}^{+} \mathrm{SP}$ $(P<0.05$, Student $t$ test $)$ and $\mathrm{CD}^{+} \mathrm{SP}(P<0.001$, Student $t$ test) thymocytes from the grid, as compared with control conditions in which thymocyte or peripheral blood $\mathrm{T}$ cell subpopulations were added to the upper chamber of the transwell containing the thymic organoid. Furthermore, when recombinant SDF-1 at a final concentration of $1 \mu \mathrm{g} / \mathrm{ml}$ was added to the lower chamber of the transwell, emigration of SP thymocytes and peripheral blood $\mathrm{T}$ cells was also inhibited (Figure 6a). This concentration of SDF-1 was chosen because we had demonstrated previously by Western blot analysis that the concentration of SDF-1 in TSCM was approximately $1.3 \mu \mathrm{g} / \mathrm{ml}$. In this way we demonstrated that emigration of SP thymocytes was dependent on both the presence of SDF-1 receptor, CXCR4, on thymocyte subpopulations and the presence of a gradient of SDF-1.

We have demonstrated previously a distinct inhibitor profile for active movement of $\mathrm{T}$ cells away from SDF-1 as compared with movement toward the chemokine for purified subpopulations of mature T cells (7). Movement both toward and away from SDF-1 was inhibitable by the phosphoinositide (PI) 3-kinase inhibitor wortmannin. Movement away from SDF-1 was significantly less sensitive to the tyrosine kinase inhibitors genistein and herbamycin than was movement toward the chemokine. The contrary was evident for the cAMP agonist 8-Br-cAMP: movement of T cells away from SDF-1 was significantly more sensitive to inhibition than was movement toward the chemokine. We therefore examined the broader inhibitor profile of the movement of SP thymocytes away from thymic fragments in order to determine whether this was similar to that seen for $T$ cells moving away from SDF-1. Thymic fragments were pretreated with inhibitors including anti-CXCR4, wortmannin, genistein, 8-Br-cGMP, and 8-Br-cAMP, and SP thymocyte emigration was subsequently quantitated using the assay system described above. Emigration of SP thymocytes from murine thymic fragments was inhibitable by pretreatment of the thymic fragment with anti-CXCR4 (12G5) $\mathrm{mAb}(53.5 \% \pm 6.5 \%$ inhibition), wortmannin $(70.2 \% \pm 2.6 \%$ inhibition), and 8 -Br-cAMP $(46.4 \% \pm 8.6 \%$ inhibition) (Figure $6 \mathrm{~b})$. In contrast, emigration of SP thymocytes from the thymic fragment was not significantly inhibited by pretreatment with the tyrosine kinase inhibitor genistein $(P=0.4$, Student $t$ test), or the cyclic nucleotide agonist 8-Br-cGMP $(P=0.2$, Student $t$ test) (Figure 6b). Therefore, the inhibitor sensitivity profile for thymic emigration in vitro resembled that which we had demonstrated previously for the active movement of mature $T$ cells away from SDF-1. These data support the hypothesis that SDF-1 generated by thymic stroma might elicit emigration of maturing $\mathrm{T}$ cells in the thymus in vivo.

\section{Table 1}

CXCR4 expression of thymocyte and peripheral blood T cell subpopulations

\begin{tabular}{|c|c|c|}
\hline Immunophenotype & $\begin{array}{c}\text { Percentage } \\
\text { of CXCR } 4^{+} \text {cells }\end{array}$ & $\begin{array}{c}\text { Mean fluorescent } \\
\text { intensity }\end{array}$ \\
\hline
\end{tabular}

Fetal thymocytes

$\mathrm{CD}^{-}{ }^{-\mathrm{CD}} 4^{-} \mathrm{CD} 8^{-}(\mathrm{TN})$

$\mathrm{CD} 4^{+} \mathrm{CD} 8^{+}(\mathrm{DP})$

$\mathrm{CD} 4^{+}(\mathrm{SP})$

$\mathrm{CD} 8^{+}(\mathrm{SP})$

$60.2 \pm 8.9$

$38.1 \pm 4.1$

$108.5 \pm 9.3$

$88.1 \pm 6.9$

$20.1 \pm 3.2$

Fetal blood $\mathrm{T}$ cells

$\mathrm{CD}^{+}{ }^{+} \mathrm{CD} 45 \mathrm{RA}^{+}$

$54.9 \pm 4.8$

$30.5 \pm 2.9$

$\mathrm{CD}^{+}{ }^{+} \mathrm{CD} 45 \mathrm{RA}^{+}$

$86.1 \pm 5.9$

$64.5 \pm 5.1$

$87.1 \pm 6.9$

$101.0 \pm 8.8$

Human fetal thymocyte and peripheral blood T cells were examined for expression of CXCR4. The percentages of cells expressing these cell surface markers \pm SEM, and mean fluorescence intensity \pm SEM, are shown. 


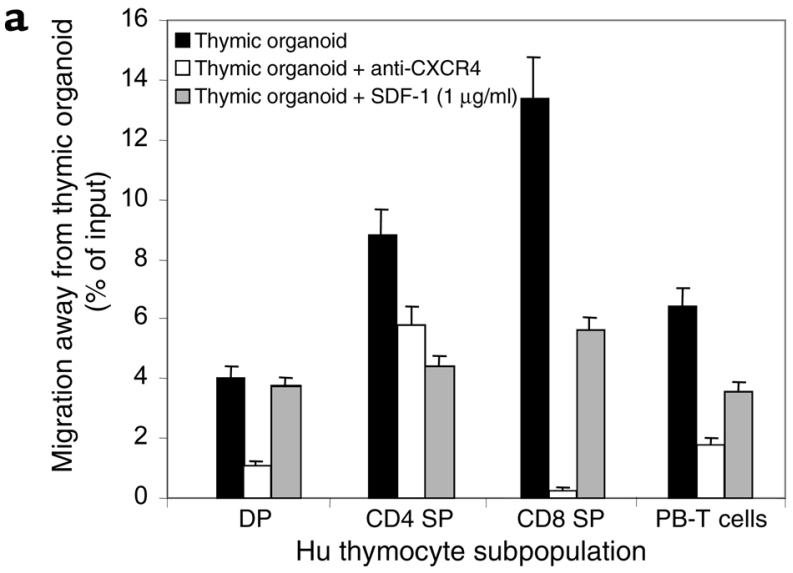

b

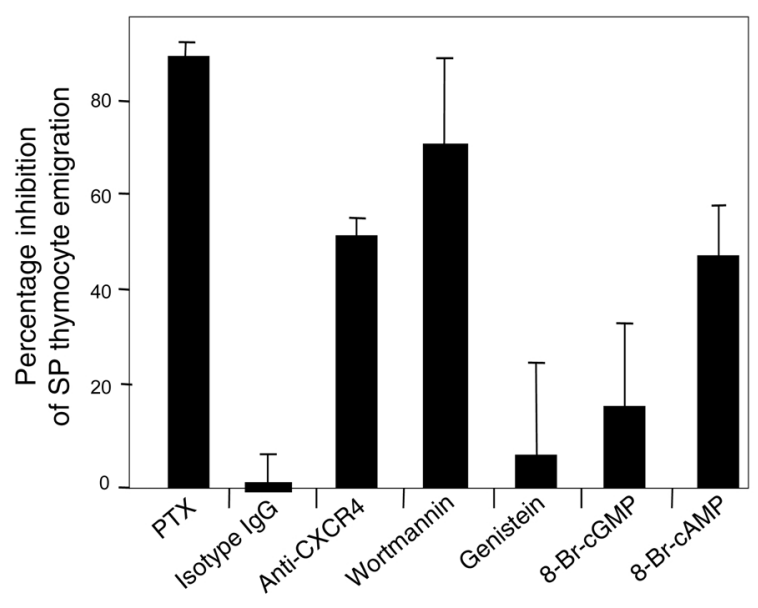

Differentiation stage-specific movement of human fetal thymocyte and $T$ cell subpopulations away from recombinant $S D F-1$. We quantitated the transmigration of purified human fetal thymocyte and peripheral blood $\mathrm{T}$ cell subpopulations in response to positive and negative gradients of SDF-1 using a standard checkerboard analysis of chemotaxis. DP and TN thymocytes demonstrated minimal migratory responses toward or away from SDF- 1 at peak concentrations of $10 \mathrm{ng} / \mathrm{ml}, 100$ $\mathrm{ng} / \mathrm{ml}, 1 \mu \mathrm{g} / \mathrm{ml}$, or $10 \mu \mathrm{g} / \mathrm{ml}$ (Figure $7 \mathrm{a}$ ).

In contrast, SP thymocytes demonstrated a peak chemotactic response to SDF-1 at a concentration of $100 \mathrm{ng} / \mathrm{ml}$, under which conditions $9.8 \% \pm 1.3 \%$ of cells transmigrated. In addition, $10.9 \% \pm 2.5 \%$ of SP thymocytes moved away from a concentration of $10 \mu \mathrm{g} / \mathrm{ml}$ (data not shown). Fetal peripheral blood $\mathrm{T}$ cell subpopulations demonstrated a bidirectional response to SDF-1, with $15.3 \% \pm 1.4 \%$ of input cells migrating toward a peak SDF-1 concentration of $100 \mathrm{ng} / \mathrm{ml}$ and $7.9 \% \pm 0.9 \%$ and $14.6 \% \pm 1.6 \%$ of cells migrating away from SDF-1 at a concentration of $1 \mu \mathrm{g} / \mathrm{ml}$ and 10 $\mu \mathrm{g} / \mathrm{ml}$, respectively (Figure $7 \mathrm{~b}$ ).

\section{Discussion}

The data presented here provide a potential mechanism by which $\mathrm{T}$ lymphocytes undergo differentiation and stage-specific emigration from the thymus. We demonstrate that mature SP thymocytes and T cells actively

\section{Figure 6}

(a) CXCR4 and SDF-1 and the emigration of SP thymocytes from thymic organoid. Purified human thymocyte subpopulations, and peripheral blood (PB) T cells were plated directly onto a three-dimensional grid coated with thymic stroma in the upper chamber of a transwell. Emigration from the grid and upper chamber into the lower chamber was quantitated (black bars). Cells in the upper chamber were pretreated with anti-CXCR4 (white bars) or SDF-1 $(1 \mu \mathrm{g} / \mathrm{ml})$ was added to the lower chamber of the transwell (gray bars) prior to the addition of purified thymocyte populations. The percentage of cells emigrating under each of the conditions was assessed in three independent experiments, and the mean migration with SE bars is shown. (b) Inhibitor profile for emigration of SP thymocytes from murine thymic tissue fragment. The $2-\mathrm{mm}^{3}$ murine thymic tissue fragments were cultured on a $3-\mu \mathrm{m}$-pore transwell membrane. The number of SP thymocytes emigrating from each tissue fragment was quantitated. Inhibitors were added to the well for the second period of 3 hours. The number and phenotype of thymocytes emigrating from each thymic tissue fragment were quantitated and compared directly with the emigrants from the first 3-hour time period. The data are expressed as the percentage of inhibition of SP thymocyte emigration from the thymic fragment in the presence of putative inhibitors of this process. Thymic fragments were treated with PTX, isotype IgG, antiCXCR4 Ab, wortmannin, genistein, 8-Br-cGMP, or 8-Br-cAMP. The data represent the mean \pm SEM for three experiments.

move away from thymic stroma and thymic fragments as a result of a process mediated by the chemokine SDF-1 and a non-SDF-1 factor or factors generated by thymic stroma. Previously, we have termed this active movement of $\mathrm{T}$ cells away from a chemokine chemofugetaxis, or fugetaxis, and suggested that this mechanism contributes to thymic emigration (7). While we use in vitro systems in this study, both the thymic organoid, previously shown to closely reiterate thymopoiesis, and freshly prepared thymic fragments demonstrate consistent data and have strong parallels with in vivo phenomena. From these in vitro assay systems we provide data that support a model of mature thymocytes migrating away from the chemokine SDF-1, thereby contributing to the previously poorly defined phenomenon of $\mathrm{T}$ cell emigration.

Emigration both in the in vitro $\mathrm{T}$ lymphopoiesis system and from thymic fragments was inhibitable by PTX, reiterating data from others that thymic emigration in vitro and in vivo is dependent on a $G_{\alpha i}$ protein-coupled receptor (GPCR) signal transduction pathway and active cell movement involving actin polymerization (3). It is well established that chemokines activate directional cell movement via PTX-sensitive $G_{\alpha i}$ protein-coupled signal transduction pathways $(11,12)$. In the case of the chemokine SDF-1, this signal is mediated through its sole GPCR on the cell surface, CXCR4 $(13,14)$. We demonstrated that emigration from thymic fragments in vitro was inhibited by anti-CXCR4, wortmannin, and 8-Br-cAMP but was relatively insensitive to inhibition by the tyrosine kinase inhibitor genistein or 8-Br-cGMP. The selective inhibition of emigration by the PI 3-kinase inhibitor wortmannin and by 8 -BrcAMP, but the reduced sensitivity of emigration to inhibition by the tyrosine kinase inhibitor genistein at low 
concentration $(3.7 \mu \mathrm{M})$, resembled the inhibitor profile seen previously for the active movement of mature $\mathrm{T}$ cells away from SDF-1 (7).

We demonstrated minimal chemokinetic activity of immature DP thymocytes to SDF-1 stimulus despite CXCR4 receptor expression in this study. A dissociation of receptor expression and function has been shown previously for $\mathrm{B}$ cells and stem cell-containing populations $(1,15)$. Our results are in apparent contrast to others where migration or calcium flux was noted in DP thymocytes following SDF-1 stimulation (16-18). There were a number of technical details distinguishing these studies, which may account for the differing results. First, we used purified populations of thymocytes, where others used pooled thymocytes and assessed the immunophenotype of those responding. Second, each of the other studies used postnatal thymic material, where we used fetal thymi. Finally, two of the studies used murine cells. The single study using human postnatal thymus demonstrated chemotaxis of thymocytes to SDF-1 but did not distinguish which subsets of cells migrated; and cells were assessed only after 18 hours, in contrast to our studies in which quantitation of transmigration was performed at 3 hours (18). It is therefore not clear whether our studies conflict with prior reports or are simply reflective of technical differences.

Chemokine signaling of $\mathrm{T}$ cell locomotion through its binding to a GPCR has been shown to activate a number of different signaling pathways, including those that are dependent on tyrosine or serine/ threonine phosphorylation involving kinases such as focal adhesion kinase and protein kinase C (19-22). However, not all cell motility is dependent on both of these pathways. For example, $\mathrm{T}$ cell locomotion has been shown to be inducible by both tyrosine kinase-dependent/genistein-sensitive and tyrosine kinase-independent/genistein-insensitive mechanisms (23). Therefore, our finding of relative insensitivity of fugetaxis to genistein has prior precedent in lymphocyte migration studies and provides an intriguing lead on the signaling mechanism governing fugetaxis.

Our data also revealed differentiation stage-specific acquisition of a fugetactic response to conditioned medium. TSCM contains both high levels of SDF-1 and a non-SDF-1 factor that induces a PTX-sensitive fugetactic response from mature $T$ cells. Fractionation of medium derived from thymic stroma suggested that emigration may be mediated by multiple $\mathrm{G \alpha}_{\mathrm{i}}$-dependent ligands, of which SDF- $1 \alpha$ is only one, a hypothesis that may support the observed absence of thymic abnormalities in CXCR4- or SDF-1-null mice $(14,24,25)$. The lack of an enlarged thymus in those settings as opposed to the lck-PTX mouse is consistent with the existence of other fugetactic factors that signal via GPCRs.

A gross defect of $\mathrm{T}$ cell development is not seen in the CXCR4- or SDF-1-deficient mouse. Although subtle T cell developmental defects and abnormalities in thymic emigration have not been formally ruled out in these knockout mice $(24,25)$, other mechanisms such as inhibition of chemotaxis may also account for these findings. a

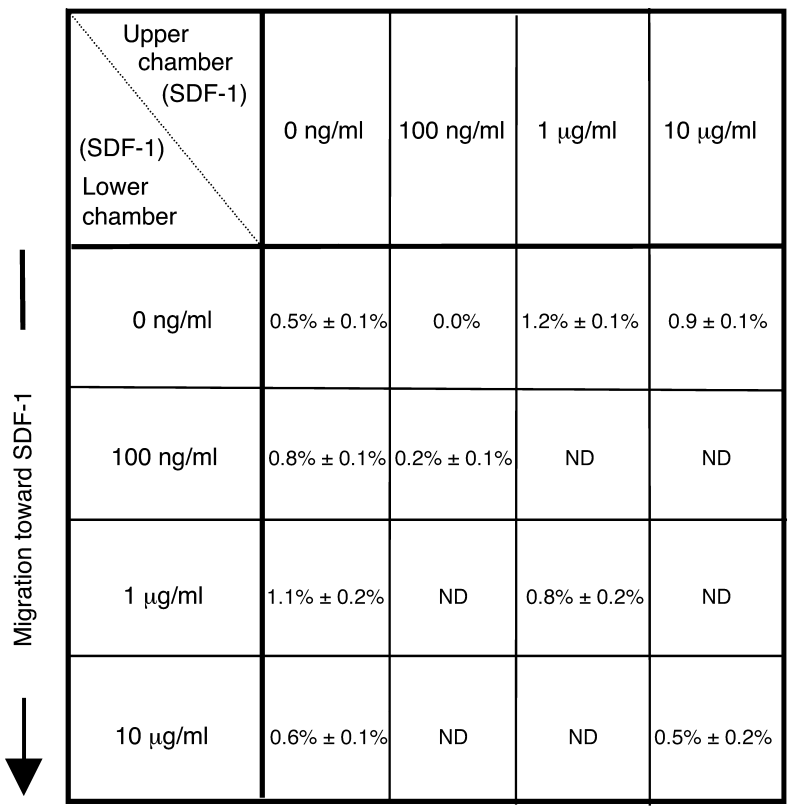

b

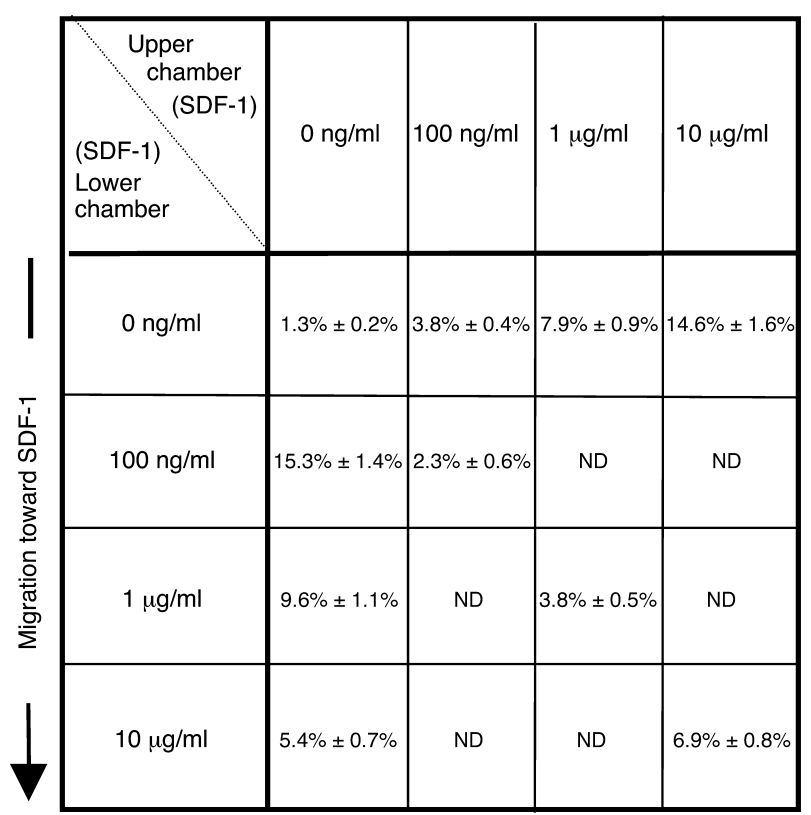

Figure 7

Checkerboard analysis of migratory responses of fetal thymocyte and T cells to SDF-1. Sorted human fetal DP thymocytes (a) or fetal blood CD4 ${ }^{+}$ $T$ cells $(\mathbf{b})$ were introduced into the upper chamber of a transwell. Numbers shown represent mean number of cells \pm SEM, from three independent experiments, that migrated through a polycarbonate membrane with a $5-\mu \mathrm{m}$ pore size into the lower chamber of a transwell. Cells were counted in the lower chamber 3 hours after the introduction of $5 \times 10^{4}$ cells into the upper chamber, and SDF- 1 was added at the indicated concentrations in the upper chamber (above diagonal), creating a negative gradient, or the lower chamber (below diagonal), creating a positive gradient. 
The results of this study also raise the issue of the non-SDF-1 fugetactic factor(s) detected in TSCM. Preliminary data have shown the fugetactic activity of this factor(s) to be heat-inactivatable and PTXand protease-sensitive. The dominant proteins in the fraction are greater than $100 \mathrm{kDa}$ in size (as determined by silver staining), suggesting that the active factor is distinct from the 8- to $10-\mathrm{kDa}$ chemokine family members. Identification of this factor(s) is likely to provide important new information regarding the spectrum of proteins capable of inducing immune cell fugetaxis.

It is possible that fugetaxis may participate in other organs of hematopoietic differentiation. For example, CXCR4-null fetal liver hematopoietic progenitor cells engraft in wild-type bone marrow when injected into the blood, yet CXCR4-null animals have no translocation of hematopoietic cells from fetal liver to bone marrow (24). The absence of CXCR4-null cells in the marrow has been considered to be due to failure of the cells to home to bone marrow. However, an alternative mechanism may be the failure of hematopoietic cells to undergo fugetaxis from the liver via a CXCR4-dependent pathway. Further experimentation will be needed to discriminate between these two plausible hypotheses.

Taken together, our data support a model in which mature $T$ cells emigrate from the thymus as a result of a fugetactic migratory response to thymic stroma-derived chemokinetic agents, including the chemokine SDF-1. SDF-1 and its receptor CXCR4 have been documented previously to be strictly regulated on thymocyte subpopulations during $\mathrm{T}$ cell development in the thymus, although a specific role for this ligand/receptor has not yet been resolved (26-30). Evidence from knockout mice suggests that the SDF-1/CXCR4 axis plays a significant role in development of the heart, gastrointestinal tract, cerebellum, and hematopoietic system $(14,24,25)$. Previously, we demonstrated that mature $T$ cells undergo fugetaxis of SDF-1 away from high concentrations in vitro and in vivo and that the high production of the chemokine in the bone marrow might exclude $\mathrm{T}$ cells from this anatomic site in vivo (7), establishing a potential pharmacological role for fugetaxis. The findings presented here provide a possible physiological role for the mechanism of fugetaxis in thymic emigration.

\section{Acknowledgments}

The authors thank Mark Van Gorder and Kathleen Sirois from the Department of Pathology at the Brigham and Women's Hospital (Boston, Massachusetts, USA) for assistance in completion of this study. The authors also thank Michael Rosenzweig and Mark Pykett (Cytomatrix) for the use of Cellfoam. This work was supported by the American Foundation for AIDS Research (to M.C. Poznansky), the NIH (DK-50234 and HL-44851 to D.T. Scadden, and AI-4 9757 to M.C. Poznansky), and the Saltonstall Charitable Foundation (to D.T. Scadden).
1. Prockop, S., and Petrie, H.T. 2000. Cell migration and the anatomic control of thymocyte precursor differentiation. Semin. Immunol. 12:435-444.

2. Norment, A.M., and Bevan, M.J. 2000. Role of chemokines in thymocyte development. Semin. Immunol. 12:445-455.

3. Lee, C.K., et al. 2001. Thymic emigrants isolated by a new method possess unique phenotypic and functional properties. Blood. 97:1360-1369.

4. Hirokawa, K., Utsuyama, M., Katsura, Y., and Sado, T. 1988. Influence of age on the proliferation and peripheralization of thymic T cells. Arch. Pathol. Lab. Med. 112:13-21.

5. Chaffin, K.E., and Perlmutter, R.M. 1991. A pertussis toxin-sensitive process controls thymocyte emigration. Eur. J. Immunol. 21:2565-2573.

6. Poznansky, M.C., et al. 2000. Efficient generation of human T cells from a tissue-engineered thymic organoid. Nat. Biotechnol. 18:729-734.

7. Poznansky, M.C., et al. 2000. Active movement of T cells away from a chemokine. Nat. Med. 6:543-548.

8. Bleul, C.C., Fuhlbrigge, R.C., Casasnovas, J.M., Aiuti, A., and Springer, T.A. 1996. A highly efficacious lymphocyte chemoattractant, stromal cell-derived factor 1 (SDF-1). J. Exp. Med. 184:1101-1109.

9. Tashiro, K., et al. 1993. Signal sequence trap: a cloning strategy for secreted proteins and type I membrane proteins. Science. 261:600-603.

10. Poznansky, M.C., et al. 2001. Tissue source dictates lineage outcome of human fetal CD34(+)CD38(-) cells. Exp. Hematol. 29:766-774.

11. Baggiolini, M. 1998. Chemokines and leukocyte traffic. Nature. 392:565-568.

12. Luster, A.D. 1998. Chemokines: chemotactic cytokines that mediate inflammation. N. Engl. J. Med. 338:436-445.

13. Tachibana, K., et al. 1998. The chemokine receptor CXCR4 is essential for vascularization of the gastrointestinal tract. Nature. 393:591-594.

14. Zou, Y.R., Kottmann, A.H., Kuroda, M., Taniuchi, I., and Littman, D.R 1998. Function of the chemokine receptor CXCR4 in haematopoiesis and in cerebellar development. Nature. 393:595-599.

15. Shen, H., et al. 2001. CXCR-4 desensitization is associated with tissue localization of hemopoietic progenitor cells. J. Immunol. 166:5027-5033.

16. Campbell, J.J., Pan, J., and Butcher, E.C. 1999. Cutting edge: developmental switches in chemokine responses during T-cell maturation. J. Immunol. 163:2353-2357.

17. Kim, C.H., Pelus, L.M., White, J.R., and Broxmeyer, H.E. 1998. Differential chemotactic behaviour of developing T-cells in response to thymic chemokines. Blood. 91:4434-4443.

18. Zaitseva, M.B., et al. 1998. CXCR4 and CCR5 on human thymocytes: biological function and role in HIV-1 infection. J. Immunol. 161:3103-3113.

19. Bacon, K.B. 1997. Analysis of signal transduction following lymphocyte activation by chemokines. Methods Enzymol. 288:340-361.

20. Selbie, L.A., and Hill, S.J. 1998. G protein-coupled-receptor cross-talk: the fine-tuning of multiple receptor-signalling pathways. Trends Pharmacol. Sci. 19:87-93.

21. Wang, J.F., Park, I.W., and Groopman, J.E. 2000. Stromal cell-derived factor-1alpha stimulates tyrosine phosphorylation of multiple focal adhesion proteins and induces migration of hematopoietic progenitor cells: roles of phosphoinositide-3 kinase and protein kinase C. Blood. 95:2505-2513.

22. Ganju, R.K., et al. 1998. The alpha-chemokine, stromal cell-derived factor-1alpha, binds to the transmembrane G-protein-coupled CXCR-4 receptor and activates multiple signal transduction pathways. J. Biol. Chem. 273:23169-23175.

23. Entschladen, F., Niggemann, B., Zanker, K.S., and Friedl, P. 1997. Differential requirement of protein tyrosine kinases and protein kinase $\mathrm{C}$ in the regulation of $\mathrm{T}$ cell locomotion in three-dimensional collagen matrices. J. Immunol. 159:3203-3210.

24. Ma, Q., Jones, D., and Springer, T.A. 1999. The chemokine receptor CXCR4 is required for the retention of $\mathrm{B}$ lineage and granulocytic precursors within the bone marrow microenvironment. Immunity. 10:463-471.

25. Ma, Q., et al. 1998. Impaired B-lymphopoiesis, myelopoiesis, and derailed cerebellar neuron migration in CXCR4- and SDF-1-deficient mice. Proc. Natl. Acad. Sci. USA. 95:9448-9453.

26. Campbell, J.J., Pan, J., and Butcher, E.C. 1999. Cutting edge: developmental switches in chemokine responses during $\mathrm{T}$ cell maturation. J. Immunol. 163:2353-2357.

27. Aiuti, A., Webb, I.J., Bleul, C., Springer, T., and Gutierrez-Ramos, J. C. 1997. The chemokine SDF-1 is a chemoattractant for human CD34 hematopoietic progenitor cells and provides a new mechanism to explain the mobilization of $\mathrm{CD} 34^{+}$progenitors to peripheral blood. J. Exp. Med. 185:111-120.

28. Aiuti, A., et al. 1999. Expression of CXCR4, the receptor for stromal cellderived factor- 1 on fetal and adult human lympho-hematopoietic progenitors. Eur. J. Immunol. 29:1823-1831.

29. Kim, C.H., and Broxmeyer, H.E. 1999. SLC/exodus2/6Ckine/TCA4 induces chemotaxis of hematopoietic progenitor cells: differential activity of ligands of CCR7, CXCR3, or CXCR4 in chemotaxis vs. suppression of progenitor proliferation. J. Leukoc. Biol. 66:455-461.

30. Suzuki, G., et al. 1999. Pertussis toxin-sensitive signal controls the trafficking of thymocytes across the corticomedullary junction in the thymus. J. Immunol. 162:5981-5985. 